\title{
Surgical management of vesicoureteral reflux in children
}

\author{
Jennifer Sung • Steven Skoog
}

Received: 1 April 2011 /Revised: 18 May 2011 /Accepted: 20 May 2011 / Published online: 22 June 2011

(C) IPNA 2011

\begin{abstract}
Vesicoureteral reflux (VUR) is the most common uropathy affecting children. Compared to children without VUR, those with VUR have a higher rate of pyelonephritis and renal scarring following urinary tract infection (UTI). Options for treatment include observation with or without antibiotic prophylaxis and surgical repair. Surgical intervention may be necessary in patients with persistent reflux, renal scarring, and recurrent or breakthrough febrile UTI. Both open and endoscopic approaches to reflux correction are successful and reduce the occurrence of febrile UTI. Estimated success rates of open and endoscopic reflux correction are $98.1 \%(95 \%$ CI 95.1, 99.1) and $83.0 \%(95 \%$ CI 69.1, 91.4), respectively. Factors that affect the success of endoscopic injection include pre-operative reflux grade and presence of functional or anatomic bladder abnormalities including voiding dysfunction and duplicated collecting systems. Few studies have evaluated the long-term outcomes of endoscopic injection, and with variable results. In patients treated endoscopically, recurrent febrile UTI occurred in $0-21 \%$, new renal damage in $9-12 \%$, and recurrent reflux in $17-47.6 \%$ of treated ureters with at least 1 year follow-up. These studies highlight the need for standardized outcome reporting and longer follow-up after endoscopic treatment.
\end{abstract}

Keywords Vesicoureteral reflux · Endoscopy · Surgery · Laparoscopy · Uropathy

J. Sung $\cdot$ S. Skoog $(\bowtie)$

Surgery, OHSU,

3303 SW Bond Ave Mail code CH10U,

Portland, OR 97239, USA

e-mail: skoogs@ohsu.edu

$\begin{array}{ll}\text { Abbreviations } & \\ \text { VUR } & \text { Vesicoureteral reflux } \\ \text { DX/HA = DHA } & \text { Dextranomer/hyaluronic acid } \\ \text { UTI } & \text { Urinary tract infection } \\ \text { UGS } & \text { Urogenital sinus } \\ \text { UVJ } & \text { Ureterovesical junction } \\ \text { VCUG } & \text { Voiding cystourethrography } \\ \text { RNC } & \text { Radionuclide cystogram } \\ \text { PTFE } & \text { Polytetrafluoroethylene } \\ \text { STING } & \text { Subureteric Teflon injection } \\ \text { HIT } & \text { Hydrodistention implantation technique } \\ \text { DMSA } & 99 \mathrm{~m} \text { Technetium-dimercaptosuccinic acid } \\ \text { AUA } & \text { American Urological Association } \\ \text { CAP } & \text { Continuous antibiotic prophylaxis }\end{array}$

\section{Introduction/Background}

Vesicoureteral reflux (VUR) represents the retrograde flow of urine from the bladder to the upper urinary tract. The true prevalence of VUR is unknown, as many children are asymptomatic. The prevalence of VUR in normal children has been estimated to be $0.4-1.8 \%$ [1]. The prevalence of VUR is significantly higher in siblings of patients with VUR (46\%), children with urinary tract infection (UTI) $(30 \%)$, infants with prenatal hydronephrosis $(16 \%)$, and in the presence of urogenital anomalies such as posterior urethral valves (PUV) $(60 \%)$, cloaca $(60 \%)$, and duplex kidney (46\%) [2-4].

\section{Embryology/Pathogenesis}

Primary VUR may be due to either abnormal position or integrity of the ureterovesical junction (UVJ). The ureter 
develops from the ureteral bud, which arises from the mesonephric or Wolffian duct during the fifth week of gestation. The distal end of the bud ultimately becomes incorporated into the part of the urogenital sinus (UGS) that becomes the trigone. Contrary to previous thought, a recent study of recombinant murine models showed that the trigone derives predominantly from bladder smooth muscle with minor contribution from ureteral smooth muscle [5]. The intramural portion of the ureter is passively compressed by the bladder wall during filling, thus preventing retrograde flow of urine. According to the Mackie-Stephens ureteral bud theory, ectopic ureteral budding leads to an ectopic ureteral orifice [6, 7]. A ureteral bud that arises low or caudal from the mesonephric duct results in superolateral displacement of the ureteral orifice, insufficient length of the intravesical submucosal ureter, and reflux. Dissections of the UVJ in non-refluxing children demonstrated an approximate tunnel length to ureteral diameter ratio of 5:1 versus to $1.4: 1$ in refluxing UVJs [8]. Interactions of the ureteral bud and well-differentiated metanephric blastema are critical to normal kidney formation. Ectopic budding may lead to interactions with poorly differentiated portions of the metanephros, resulting in renal malformations as dysplasia, hypoplasia, or agenesis, collectively referred to as congenital reflux nephropathy.

\section{Evaluation/Grading}

Voiding cystourethrography (VCUG) is the gold standard for diagnosis of reflux. This is a fluoroscopic study in which the bladder is gravity-filled with contrast using a urethral catheter. A VCUG can be performed following clinical or culture evidence that an active urinary infection has been adequately treated. The radionuclide cystogram (RNC) may also be used to detect reflux with the advantage of reduced radiation exposure. However, this study provides less anatomic detail (e.g., does not show calyceal architecture or detect posterior urethral valves) compared to the standard VCUG and should not be performed for initial evaluation of males. In our experience, RNC has been used in the follow-up evaluation of patients diagnosed with reflux.

Medical evaluation of children with reflux should include measurement of height, weight, blood pressure, urinalysis for proteinuria and bacteruria, and serum creatinine in the presence of bilateral cortical abnormalities [9]. A grading system for reflux was established by the International Reflux Study Committee established in 1981 to aid with clinical management and prognostication. Five grades are defined based on the extent of reflux and degree of dilation of the upper tract on imaging [10,11] (Fig. 1).

\section{Natural history}

Spontaneous resolution of primary reflux is common. This is thought to be multi-factorial, due in part to remodeling of the UVJ, elongation of the intravesical ureter, and stabilization of bladder voiding dynamics over time. At birth, the likelihood of spontaneous resolution is inversely proportional to the initial grade of reflux; approximately $80 \%$ of low-grade (I and II) reflux will resolve spontaneously vs. about $50 \%$ of grade III reflux. Few or approximately $20 \%$ of high-grade (IV and V) reflux will resolve [12]. For older children, resolution depends on both initial grade of reflux, gender, and age at initial diagnosis [13]. Other factors that affect reflux resolution include voiding dysfunction, presence of renal scarring, and occurrence of reflux during bladder filling or emptying. In general, reflux is more likely to resolve in younger patients with low-grade reflux and normal renal ultrasound.

\section{Rationale/Indications for surgical management}

Decisions for surgical repair are individualized and based on patient age, health, reflux grade, clinical course, compliance, renal scarring, and parental preference. Prevention of febrile UTI or pyelonephritis is one of the primary goals of surgical management. Surgical cure of VUR reduces the occurrence of pyelonephritis, though it has not been proven to reduce renal injury. Patients with recurrent pyelonephritis and/or persistent reflux benefit most from surgery [14].

A systematic review of 33 studies evaluating ${ }^{99} \mathrm{~m}_{\text {technetium- }}$ dimercaptosuccinic acid (DMSA) scan abnormalities in children with initial UTI demonstrated that $57 \%$ of children had changes consistent with acute pyelonephritis on acute-phase DMSA scan and $15 \%$ had renal scarring on follow-up DMSA scan [15]. Approximately $25 \%$ of children with a first UTI had VUR and were significantly more likely to develop both pyelonephritis (RR 1.5 [95\% CI: 1.1-1.9]) and renal scarring (RR 2.6 [95\% CI: 1.73.9]), compared to children without VUR [15].

Recommendations for treatment were published by the pediatric VUR guidelines panel of the American Urological Association (AUA) in 1997 [16]. Factors included in these recommendations were patient age at presentation, grade of reflux, unilateral vs. bilateral reflux, persistent reflux on follow-up, and presence or absence of renal scarring. In general, surgical intervention was recommended in patients who were older at initial presentation, and had dilating, bilateral, or persistent reflux, and renal scarring. Following FDA approval of Deflux ${ }^{\circledR}$ as a bulking agent for the treatment of VUR grades 1-4, the 2010 AUA guidelines were revised to include endoscopic treatment of reflux for patients with febrile break-through UTI [1]. 
Fig. 1 International classification of Vesicoureteral reflux [11], used with permission a
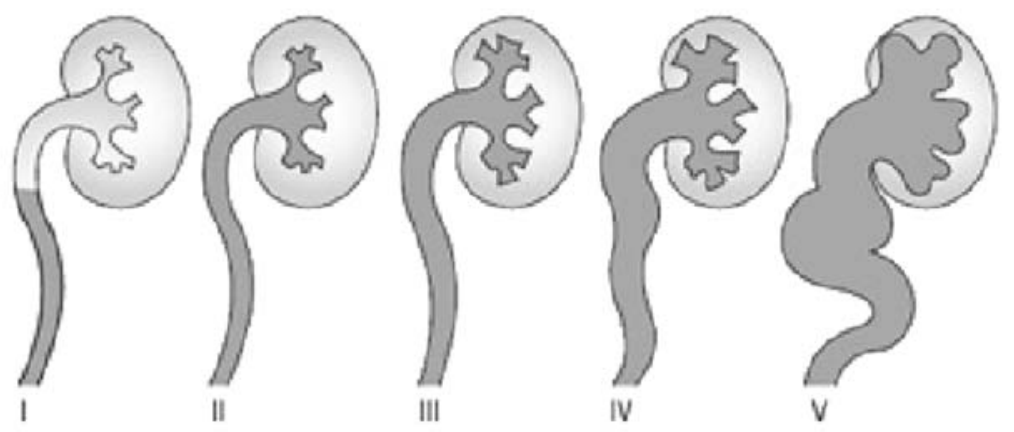

b

\begin{tabular}{|c|l|}
\hline Grade & \multicolumn{1}{|c|}{ Description } \\
\hline I & Into a nondilated ureter \\
\hline II & Into the pelvis and calyces without dilatation \\
\hline III & Mild to moderate dilatation of the ureter, renal pelvis, and calyces with minimal blunting of the fornices \\
\hline IV & Moderate ureteral tortuosity and dilatation of the pelvis and calyces \\
\hline V & Gross dilatation of the ureter, pelvis, and calyces; loss of papillary impressions; and ureteral tortuosity \\
\hline
\end{tabular}

Relative indications for surgical correction:

- High-grade reflux

- Low probability of spontaneous resolution [17]

- Renal scarring

- Recurrent pyelonephritis

- Breakthrough febrile UTI while on continuous antibiotic prophylaxis

- Parental preference

\section{Surgical treatment of VUR}

Options for surgical repair of VUR include open, laparoscopic, and endoscopic techniques.

\section{Open repair}

Open repairs prevent reflux by increasing the length of the intravesical ureter, facilitating compression of the ureter against the detrusor muscle during bladder filling (Table 1). These procedures generally require inpatient hospitalization for management of post-operative pain as well as temporary urinary catheter drainage. In contrast, endoscopic repair is an outpatient procedure with minimal post-operative pain and no need for urinary catheter. The reduced morbidity of endoscopic repair, however, may come at the cost of decreased surgical success.

The estimated success rate of open surgery is $98.1 \%$ (95\% CI 95.1, 99.1) [1]. Prospective randomized controlled studies comparing open surgical correction of VUR and continuous antibiotic prophylaxis (CAP) have shown a reduction in the occurrence of febrile UTIs, but no difference in the rates of renal scarring. Ten-year results of the International Reflux Study in Children demonstrated recurrent febrile UTI in 14\% of patients treated with open surgical repair versus $25 \%$ treated with antibiotic prophylaxis [18]. There was no difference in the incidence of new renal scar following antibiotic treatment (6-12\%) or open surgical repair (5-14\%) [18-20]. Complications of open surgical repair include obstruction (2\%) and contralateral reflux (9\%) [16].

Various open approaches have been described including extravesical, intravesical, as well as combined approaches. In 1952, Hutch initially described the technique of elongating the intravesical ureter to create an anti-reflux valve in paraplegic patients with VUR [21]. Since then, multiple additional techniques have been described.

\section{Extravesical}

Lich-Gregoir (1961, 1964): The juxtavesical ureter is dissected and a submucosal groove is created extending laterally from the ureteral hiatus along the course of the ureter. The ureter is placed in the groove and the detrusor is closed over the ureter [22-24].

Advantages: This technique does not require bladder opening or ureteral stent placement.

Disadvantages: There is an increased risk for pelvic nerve damage and urinary retention, especially for bilateral procedures, and is not performed within the first year of life. 
Table 1 Open Surgery

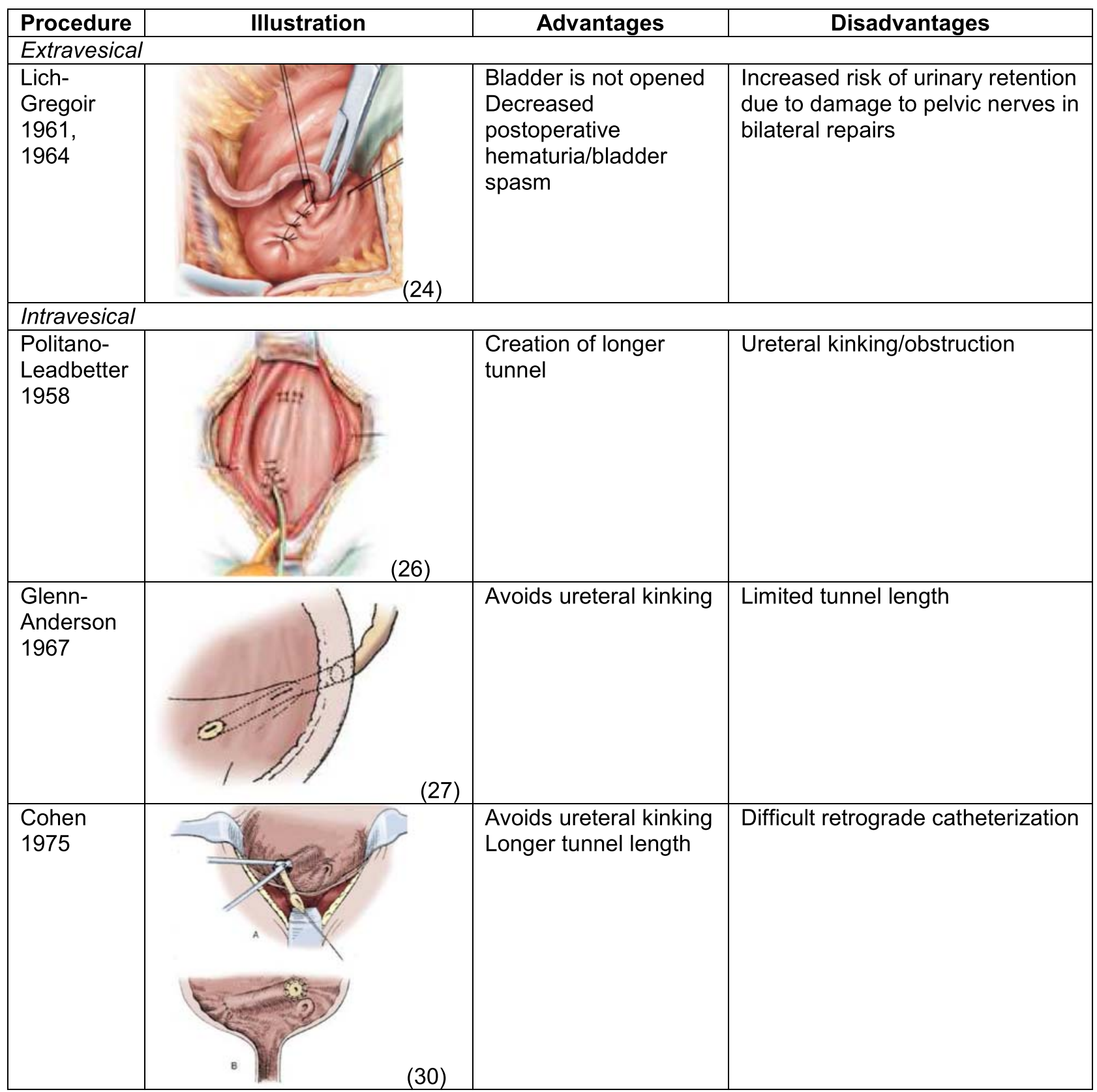

The illustrations used in this table are from the references $24,26,27,30$, and are used with permission.

Intravesical

Politano-Leadbetter (1958): The ureter is mobilized intravesically and then brought through a new muscular hiatus located superior and lateral to the original mucosal orifice $[25,26]$.

Advantages: This technique enables creation of a longer tunnel, which is useful in higher grades of reflux.

Disadvantages: In addition to postoperative hematuria, patients are at risk for ureteral kinking/obstruction and bowel injury.
Glenn-Anderson (1967): The ureter is advanced distally through a submucosal tunnel extending inferomedially towards the bladder neck. A later modification with proximal incision of the detrusor at the original hiatus enabled creation of a longer tunnel [27, 28].

Advantages: There is a reduced risk for ureteral kinking/ obstruction with this technique.

Disadvantages: The distal ureteral anastomosis may be challenging due to proximity to the bladder neck.

Cohen (1975): The ureter is advanced through a submucosal tunnel across the trigone to the contralateral 
bladder wall with the new mucosal orifice located superior to the contralateral orifice $[29,30]$.

Advantages: This technique enables creation of a longer tunnel length and avoids ureteral kinking.

Disadvantages: Retrograde catheterization is difficult following repair.

\section{Laparoscopic repair}

Laparoscopic approaches to reflux repair were first described in the mid-1990s [31, 32]. Intravesical and extravesical approaches have been described with the latter being more common. Theoretical advantages include decreased hospital stay, decreased postoperative pain/analgesic requirement, smaller incisions, and faster recovery. Early results demonstrate similar efficacy to open procedures, with success rates of $88-100 \%$, but technical difficulty, longer operative times, and higher rate of complications including ureteral injury/obstruction, urine leak, and fistula, have precluded widespread adoption [33]. Other minimally invasive techniques including pneumovesiscopic and robotic-assisted approached have been described, however, further studies are required to demonstrate the benefit over standard open repairs.

\section{Endoscopic repair}

Endoscopic repairs prevent reflux by injection of a bulking agent to allow elevation and coaptation of the ureteral orifice and ureteral wall [34]. Benefits include outpatient surgery, lower cost, and decreased patient morbidity. Various methods of injection (sub-ureteral and intraureteral) and injectable materials have been described. In a systematic meta-analysis evaluating endoscopic treatment of pediatric VUR, the estimated success rate for endoscopic therapy after a single injection was $83.0 \%$ (95\% CI 69.1, 91.4) [1]. Presence of bladder and bowel dysfunction does not affect the cure rate for open surgical procedures but does for endoscopic procedures.

The ideal injectable material should have the following qualities:

- Durable, effective, safe

- Inert, easily injectable, stable with time

- Must not extrude or migrate

- Biocompatible, non-antigenic, non-carcinogenic

Initial reports of endoscopic injections were with a polytetrafluoroethylene (PTFE) paste, however, this substance was not approved for use in the United States due to migration to other organ sites. Dextranomer hyaluronic acid (Dx/HA or Deflux ${ }^{\circledR}$ ) was approved by the FDA in 2001 for the treatment of VUR grades $1-4$. Dx/HA copolymer is a viscous gel consisting of two sugar-based molecules: Dextranomer (Dx) microspheres suspended in non-animal hyaluronic acid (HA). In contrast to PTFE, Dx/HA microspheres are larger in size $(80-250 \mu \mathrm{m})$ and therefore less likely to embolize or migrate. Other bulking agents include Macroplastique $^{\circledR}$ (polydimethylsiloxane particles suspended in polyvinylpyrrolidone or PVP carrier gel) and collagen; the latter is antigenic and may be absorbed.

Sub-ureteral - "STING"

Endoscopic treatment of VUR was first described by O'Donnell and Puri in 1984 (Fig. 2). They performed subureteric Teflon injection (STING) in 13 patients with reflux. A total of $78 \%$ had resolution of reflux after a single injection [35]. The same group later reported their experience after treatment of 1,101 ureters. Success rates following single injection were 100, 93.1, 77.7, and

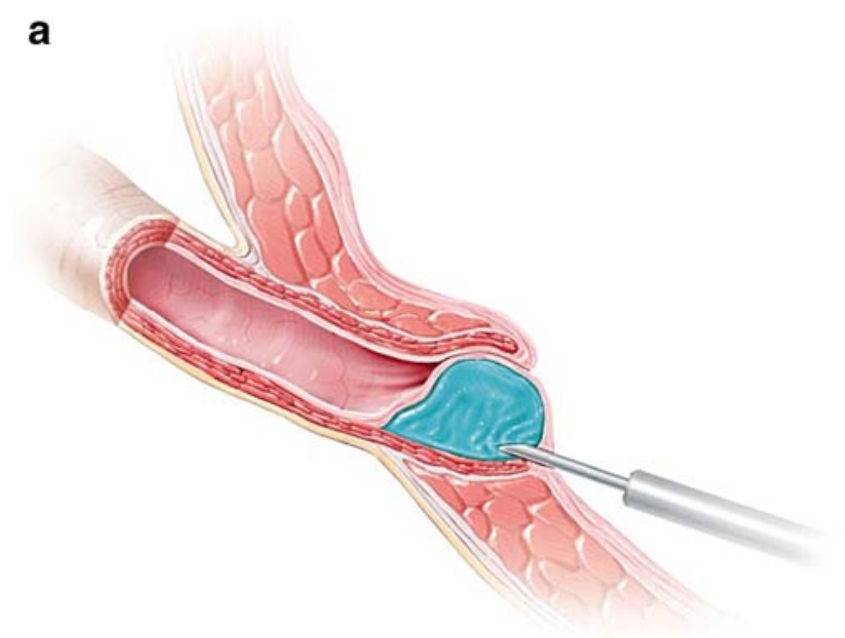

b

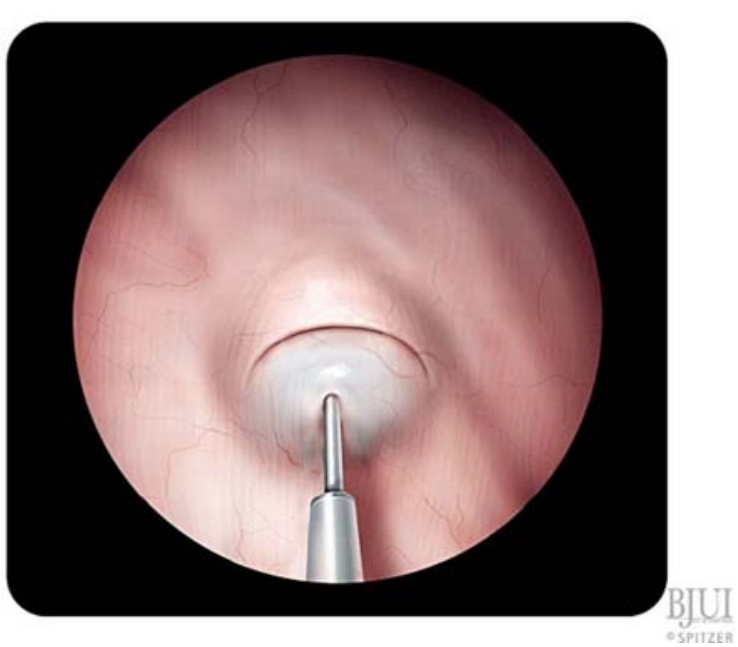

Fig. 2 STING [34], used with permission 
$75.9 \%$ for grades II through V reflux, respectively [36]. Most of these patients had grade III or IV reflux. Only reflux grade and younger patient age were independent risk factors associated with failure on logistic regression analysis.

Intraureteral - "HIT"

In 2004, Kirsch described a modification called the hydrodistention implantation technique (HIT) (Figs. 3, 4, 5). The needle is advanced into the ureteral tunnel and $\mathrm{Dx} / \mathrm{Ha}$ is injected along the entire length of the detrusor tunnel for maximal coaptation. A total of $89 \%$ of patients undergoing HIT had resolution of reflux versus 79\% undergoing standard STING [37]. HIT was further modified to include two intraureteral injections (proximal and distal), for total ureteral tunnel coaptation. The goals of "double HIT" are to create a "mountain range appearance" of the ureteral tunnel and eliminate hydrodistention [38]. Success rates ranged from 70 to $95 \%$.

\section{a}

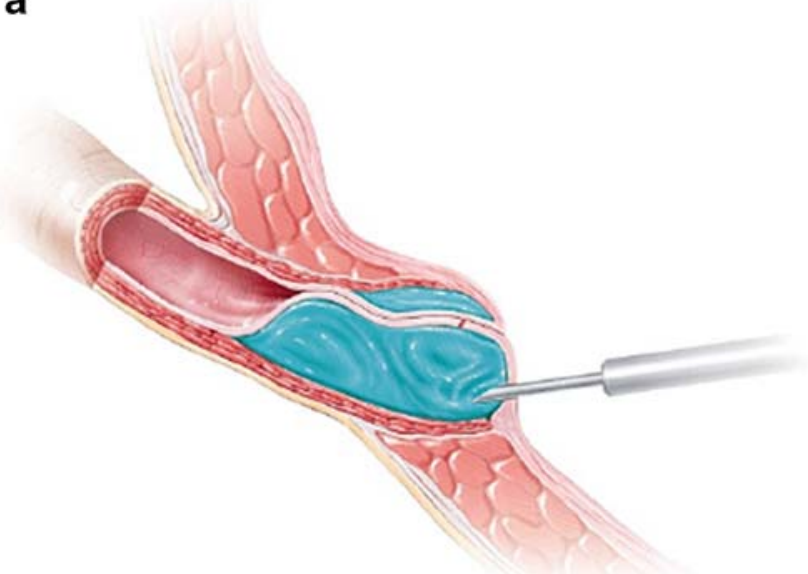

b

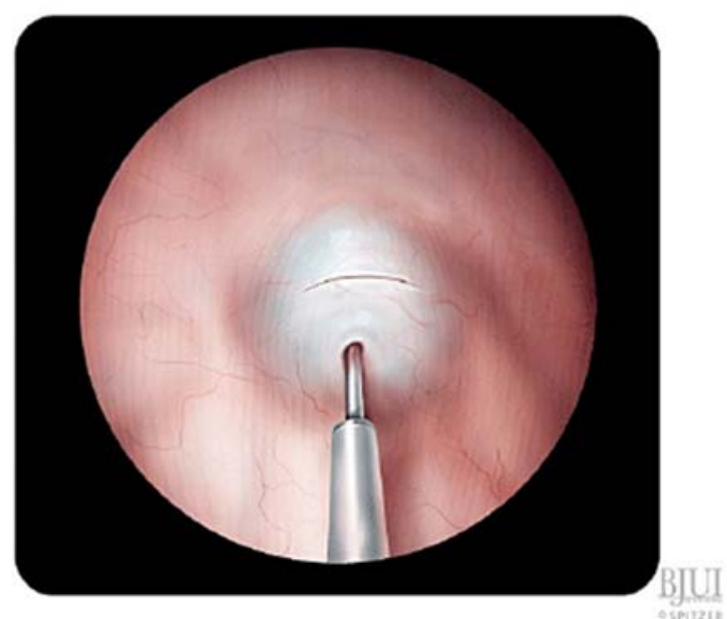

Fig. 3 Double HIT [34], used with permission
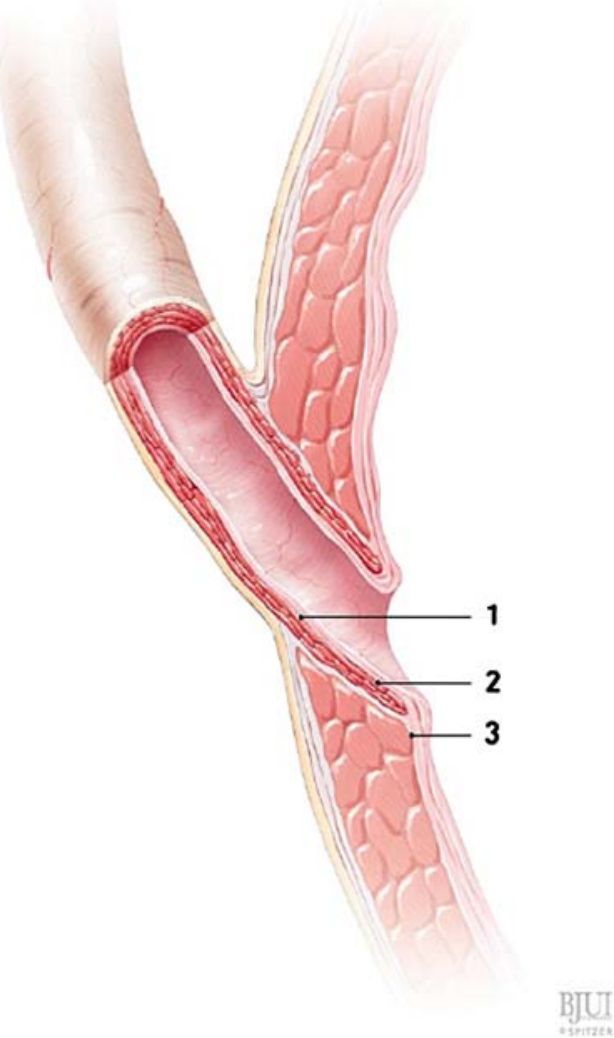

Fig. 4 Injection sites bulking material is injected at sites 1 and 2 for the double HIT method, and site 3 for the STING method [34], used with permission

Subsequent multivariate analyses have failed to demonstrate a significant difference in outcomes between STING and HIT techniques [39-41]. Other factors that have been evaluated as potential predictors of endoscopic injection

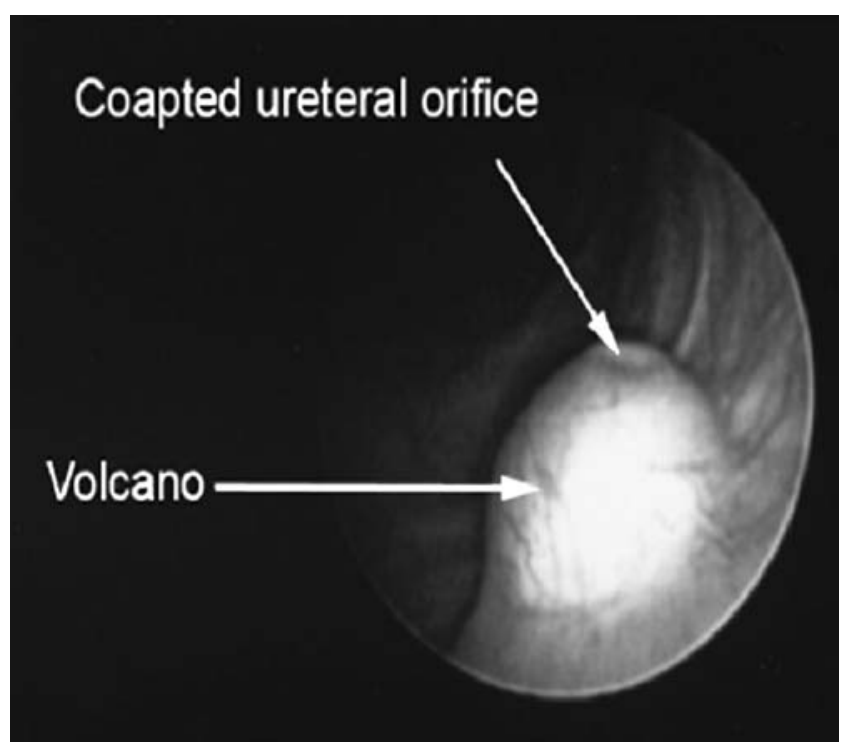

Fig. 5 Morphology of injected mound 
success include pre-operative reflux grade, functional/ anatomic abnormalities, voiding dysfunction, injected volume, mound morphology/location, surgeon factors/experience, and duration of follow-up [42, 43]. While patients with higher pre-operative reflux grade and voiding dysfunction have lower success rates with endoscopic injection, injection technique and volume do not appear to be significant predictors of success.

\section{Outcomes}

Resolution of reflux

\section{Short-term results}

There is considerable evidence including level 1 and 2 data, supporting the use of endoscopic injection in the treatment of VUR grades 1-4 in pediatric patients [44-46]. These studies demonstrate single-injection, per-ureter reflux resolution rates ranging from 52 to $77 \%$ (Table 2). In one metaanalysis [45], individual study success ranged from 44 to $92 \%$. Not surprisingly, $87 \%$ of this variability was related to between-study variability. There are several potential explanations for these discrepancies. First, definitions of "success" differ among authors. In the US, treatment success is typically defined as grade 0 or no reflux, while other authors have defined success as grade 2 or less reflux. Second, there is variability among patient populations since not all studies include patients with functional/anatomic bladder abnormalities such as voiding dysfunction, neuropathic bladder, duplicated systems, and ureteroceles. Third, differences in injection technique and bulking agents have evolved over time and may account for some variability in outcomes. These discrepancies highlight the need for more standardized study designs and outcome reporting in the future. Despite these limitations, the evidence indicates that endoscopic injection is effective for the treatment of most

Table 2 Outcomes of single endoscopic injection with DHA

\begin{tabular}{|c|c|c|c|c|c|c|c|c|c|c|}
\hline LOE & Study & Year & $\begin{array}{l}\text { Patients/ } \\
\text { ureters }\end{array}$ & $\begin{array}{l}\text { Pre-op } \\
\text { VUR } \\
\text { grade }\end{array}$ & $\begin{array}{l}\text { Success } \\
\text { rate }^{\mathrm{a}}\end{array}$ & $\begin{array}{l}\text { Last } \\
\text { VCUG } \\
\text { years } \\
\text { after } \\
\text { Tx }\end{array}$ & $\begin{array}{l}\text { Patients/ } \\
\text { ureters w/late } \\
\text { VCUG }\end{array}$ & $\begin{array}{l}\text { Recurrent VUR } \\
\text { No ureters }(\%)^{\mathrm{b}}\end{array}$ & $\begin{array}{l}\text { Febrile UTI No } \\
\text { patients (\%) }\end{array}$ & $\begin{array}{l}\text { NF-UTI No } \\
\text { patients (\%) }\end{array}$ \\
\hline $1 b$ & Läckgren [47] & 2001 & $221 / 334$ & $3-5$ & $54 \% *$ & $2-5$ & $49 / 77$ & $\begin{array}{l}13(17 \%) \mathrm{G} 3-4 \\
20(26 \%) \mathrm{G} 2-4\end{array}$ & $8 / 221(3.5 \%)$ & $11 / 221(4.8 \%)$ \\
\hline $1 b$ & Oswald [48] & 2002 & $38 / 56$ & $2-4$ & $\begin{array}{l}71.4 \% * \\
62.5 \% \\
* *\end{array}$ & 1 & $22 / 32$ & $10(31.2 \%)$ & - & - \\
\hline $2 b$ & Kirsch [60] & 2003 & $180^{\zeta} / 292$ & $1-4$ & $72 \% * *$ & - & - & - & - & - \\
\hline $1 \mathrm{a}$ & Elder $^{\mathrm{c}}$ [44], [60] & 2006 & $\begin{array}{r}5,527 / \\
8,101\end{array}$ & $1-5$ & $\begin{array}{c}75.7 \% \\
* * *\end{array}$ & - & - & - & $0.75 \%$ & $6 \%$ \\
\hline $2 b$ & Lee [49] & 2009 & $219 / 337$ & $1-5$ & $73 \% * *$ & 1 & $-/ 150$ & $39(26 \%)$ & - & - \\
\hline $2 b$ & Chertin [54] & 2009 & $\begin{array}{l}\text { 507/696 } \\
\text { PTFE or } \\
\text { DHA }\end{array}$ & $1-5$ & $68 \% * *$ & $1-12$ & $11 /-$ & $\begin{array}{c}8(72.7 \%)^{\psi} \\
(3 \mathrm{DHA})\end{array}$ & $\begin{array}{l}11 / 507(2.2 \%) \\
(3 \mathrm{DHA})\end{array}$ & $28 / 507(5.6 \%)$ \\
\hline $2 b$ & Hsieh [50] & 2010 & $166 / 265$ & $1-5$ & $\begin{array}{l}86.4 \% \\
* *\end{array}$ & 1 & $44 /-$ & - & $0 / 44(0 \%)$ & $11 / 44(25 \%)$ \\
\hline $1 b$ & $\begin{array}{l}\text { Holmdahl [46] } \\
\text { Brandström [51] }\end{array}$ & 2010 & $66 / 82$ & $3-4$ & $\begin{array}{l}54.5 \% * \\
52 \% * *\end{array}$ & 2 & $\begin{array}{l}52 / 63 \\
66 /-\end{array}$ & $\begin{array}{l}30(47.6 \%) \text { G2-4 } \\
13(20 \%)^{\psi} \text { G3-4 }\end{array}$ & $14 / 66(21 \%)$ & - \\
\hline $2 \mathrm{a}$ & Routh [45] & 2010 & $-/ 7,303$ & $1-5$ & $\begin{array}{l}77 \% \\
* * *\end{array}$ & - & - & - & - & - \\
\hline
\end{tabular}

\footnotetext{
${ }^{a}$ All reported as per-ureter success rate following single injection except Läckgren and Kirsch (per-patient success rate)

${ }^{\mathrm{b}}$ All reported as per ureter recurrence rate except Chertin and Holmdahl (per-patient recurrence rate)

${ }^{\mathrm{c}}$ Analysis includes studies using non-DHA bulking agents

$L O E$ Level of evidence; $N F$ Non-febrile

$*$ Success $\leq$ grade 1 reflux

$* *$ Success $=$ no reflux

*** Success varies with each author's definition

${ }^{\psi}$ Per-patient recurrence rate

¿ 134 patients had 3-month follow-up and were included in analysis
} 
VUR, while emphasizing the importance of pre-operative reflux grade and structural/functional bladder abnormalities in ultimate treatment success.

\section{Long-term results}

Due to recent reports of recurrent reflux following successful endoscopic injection, increased attention has been focused on treatment durability. Most patients who receive endoscopic injection are evaluated with a post-operative VCUG at 3 months. Few patients will undergo additional VCUG unless clinically indicated by febrile UTI. Thus, the long-term efficacy of endoscopic injection is not known.

Several groups have published long-term results after endoscopic injection [47-51]. The time of last post-operative VCUG ranged from 1 to 12 years (Table 2). Recurrent reflux occurred in 17 to $47.6 \%$ of ureters, with a median of $26 \%$. The incidence of febrile and non-febrile UTI following injection ranged from $0-21 \%$ and $5.6-25 \%$, respectively. With the exception of the Swedish trial, these were lower than previously published UTI rates following open surgical correction of reflux ( $8 \%$ pyelonephritis, $32-39 \%$ cystitis) [52].

Several factors likely play a role in the variability of reported outcomes. These include small patient numbers, presence of varying degrees of anatomic/functional bladder abnormalities, and differences in injection techniques, definitions of reflux recurrence, and methods of calculating recurrence. Most studies defined recurrent reflux as grade 2 or higher reflux and limited repeat VCUGs to patients diagnosed with febrile UTI. Thus, the true rate of reflux recurrence cannot be measured. Of note, the Swedish trial $[46,51]$ was the only prospective randomized trial evaluating VUR status and recurrent UTI. In this study, $20 \%$ of patients developed recurrent dilating reflux following endoscopic injection at 2-year VCUG. A total of $21 \%$ of patients in the endoscopic treatment arm had one or more recurrent febrile UTI following injection. The incidence of recurrent UTI was 2-3 times higher among girls in the surveillance (57\%) versus antibiotic prophylaxis (19\%) and endoscopic (23\%) arms. Further analysis showed that compared to controls, both endoscopic treatment and antibiotic prophylaxis significantly decreased the rate of recurrent febrile UTI in girls with grade 3-4 VUR. There was no benefit from treatment in boys greater than 1 year of age with dilating VUR.

Taken together, the data suggest that a significant fraction of patients with successful endoscopic injection on initial VCUG may ultimately develop recurrent reflux. In addition, up to $20 \%$ of patients treated with endoscopic injection may develop recurrent febrile UTI, with girls at greater risk than boys. For these reasons, longer follow-up and repeat VCUG may be warranted to evaluate for late failures.

\section{Renal damage}

Two studies [53, 54] have evaluated the development of new renal damage, which includes both renal deterioration and scarring, following treatment of reflux with endoscopic injection. Patients were evaluated with pre- and postoperative DMSA scan; those with functional/anatomic bladder abnormalities were excluded. Pre-operative renal scarring was present in $78 \%$ and $61 \%$ of renal units and patients, respectively. New, post-operative renal deterioration and scarring developed in $7.5 \%$ of renal units and $9.1 \%$ of patients, respectively. In the Swedish trial, there was no statistical difference in renal status deterioration (new renal scar of $>3 \%$ decreased relative function) among surveillance (18\%), endoscopic (12\%), and antibiotic prophylaxis $(6 \%)$ groups. Renal damage was strongly associated with recurrent febrile UTI and new renal scarring was highest in girls in the surveillance arm with dilating reflux at study entry. These data demonstrate that new renal damage following endoscopic injection is relatively uncommon. Nonetheless, it may still occur, particularly in female patients presenting with febrile UTI. Given this risk, prompt evaluation and treatment of febrile UTI should be initiated in patients who have been previously treated with endoscopic injection.

\section{Discussion}

Vesicoureteral reflux is the most common uropathy in children. Although spontaneous resolution in primary reflux is common, surgical intervention may be necessary in patients with persistent reflux, recurrent pyelonephritis, renal scarring, or breakthrough febrile UTI. Both open and endoscopic approaches to reflux correction are highly successful and reduce the occurrence of febrile UTI. In comparison, no difference has been shown in the incidence of new renal damage following open surgical correction or antibiotic prophylaxis (5-14\% vs. $6-12 \%$, respectively). In addition, the incidence of new renal damage after endoscopic treatment appears to be comparable (9-12\%) to open correction; however, there has been no study directly comparing outcomes of open and endoscopic correction of reflux.

Decisions for surgical repair and type of repair are individualized. The choice of surgical modality is based on reflux grade, treatment efficacy/morbidity, and family preference. With the advent of Dx/HA copolymer, endoscopic therapy has become the first-line therapy for many patients with reflux. In contrast to antibiotic prophylaxis, endoscopic injection offers an immediate cure with minimal adverse effects and is independent of patient compliance. 
Compared to open repair, endoscopic therapy is associated with decreased patient morbidity and possibly lower costs. Studies evaluating the cost-effectiveness of endoscopic treatment suggest that it may be superior to open ureteral reimplantation in some settings; however, it is unclear if this advantage remains in cases of high-grade, bilateral, and recurrent reflux $[55,56]$. A recent study on the treatment patterns of reflux showed that $80 \%$ of parents of patients with moderately severe VUR chose endoscopic injection when given information on each of the treatment options [57]. Both the opinion of the pediatric urologist and the individual hospital at which the patient seeks treatment influenced the procedure performed $[58,59]$.

Given the success of endoscopic therapy, the 2010 AUA guidelines were revised to include this treatment modality in the management options for VUR. "It is recommended that patients receiving CAP with a febrile breakthrough UTI be considered for open surgical ureteral reimplantation or endoscopic injection of bulking agents for intervention with curative intent" [1]. In addition, these guidelines outline indications for post-operative imaging in patients who have received definitive treatment for VUR. "With the occurrence of a febrile UTI following resolution or surgical treatment of VUR, evaluation for bladder and bowel dysfunction or recurrent VUR is recommended." Though endoscopic injection may be successful in most patients with primary reflux (grades 1-4), it is our opinion that open repair may be indicated in complex patients with voiding dysfunction, anatomic abnormalities, or those who have failed prior endoscopic injections.

\section{Conclusions}

Endoscopic injection of dextranomer/hyaluronic acid (DHA) has emerged as a highly successful, minimally invasive therapy for VUR. Multiple studies have demonstrated safety and efficacy of this treatment modality for the correction of reflux. Success rates are comparable to open surgery with added benefits of being an outpatient procedure and minimal associated morbidity. The most important predictors of success include pre-operative reflux grade and the absence of functional/anatomic bladder abnormalities including voiding dysfunction, neuropathic bladder, duplicated systems, and ureterocele. Given recent reports of late failures, additional studies are needed to determine treatment durability. In addition, longer followup and repeat VCUG may be warranted, particularly in patients with febrile UTI following treatment with Deflux ${ }^{\circledR}$. Despite these limitations, endoscopic injection is effective in most children and should be considered as an option in the management of persistent VUR.

\section{Summary points}

- Children with VUR are more likely to develop acute pyelonephritis and renal scarring compared to children without VUR.

- Surgical correction of VUR reduces the occurrence of febrile UTIs.

- The 2010 AUA guidelines recommend consideration of surgical (open or endoscopic) correction of VUR in patients receiving continuous antibiotic prophylaxis with a febrile breakthrough UTI.

- Pre-operative reflux grade is the single most important factor affecting the success rate of endoscopic injection.

- Patients with febrile UTI following treatment with endoscopic injection should be evaluated with VCUG to rule out recurrent VUR.

\section{Research points}

- Multivariate analyses have not shown a significant difference in outcomes between intraureteral and subureteral injection techniques.

- Technical factors affecting the success of endoscopic injection need further refinement.

- Small patient numbers and differences in injection techniques, study design, patient characteristics, and definition/calculation of reflux recurrence contribute to the wide variability in long-term results after endoscopic injection.

- Additional studies with standardized outcome reporting and longer follow-up are needed to evaluate the durability of endoscopic injection.

- Further studies are needed to evaluate the risk and clinical significance of renal damage following treatment with endoscopic injection.

Multiple choice questions: answers appear following the reference list.

1. What is the success rate of endoscopic injection for treatment of VUR
a. $30-40 \%$
b. $50-60 \%$
c. $70-80 \%$
d. $90-95 \%$

2. What is the risk of renal scarring following first UTI
a. $5 \%$
b. $10 \%$
c. $15 \%$
d. $25 \%$ 
3. All of the following are recommendations based on the 2010 AUA guidelines for the treatment of VUR, except:

a. A VCUG should be performed following a febrile UTI in a child with prior successful endoscopic treatment.

b. Surgical correction is recommended for patients on antibiotic prophylaxis with febrile break-through UTI.

c. Either endoscopic or open repair of VUR are acceptable options for surgical correction.

d. Endoscopic injection is effective for the treatment of grade 5 VUR.

4. The only factor which has been demonstrated to significantly influence DHA injection success rate is:
a. Surgeon experience
b. Pre-operative VUR grade
c. Injection volume
d. Conflict of interest

5. Which of the following is not true of endoscopic treatment of reflux:

a. Entails injection of a bulking agent, allowing coaptation of the ureteral orifice.

b. Sub-ureteral and intraureteral injection techniques have been described.

c. Presence of bladder and bowel dysfunction does not affect the cure rate.

d. Benefits include outpatient surgery and decreased patient morbidity.

\section{References}

1. Bailey RR (1979) Vesicoureteral reflux in healthy infants and children. Reflux Nephropathy 59-61

2. Sargent MA (2000) What is the normal prevalence of vesicoureteral reflux? Pediatr Radiol 30:587-593

3. Skoog SJ, Peters CA, Arant BS Jr, Copp HL, Elder JS, Hudson RG, Khoury AE, Lorenzo AJ, Pohl HG, Shapiro E, Snodgrass WT, Diaz M (2010) Pediatric vesicoureteral reflux guideline panel summary report: clinical practice guidelines for screening siblings of children with vesicoureteral reflux and neonates/infants with prenatal hydronephrosis. J Urol 184 (3): 1145-1151

4. Zerin JM, Ritchey ML, Chang AC (1993) Incidental vesicoureteral reflux in neonates with antenatally detected hydronephrosis and other renal abnormalities. Radiol 187:157-160

5. Viana R, Batourina E, Huang H, Dressler GR, Kobayashi A, Behringer RR, Shapiro E, Hensle T, Lambert S, Mendelsohn C (2007) The development of the bladder trigone, the center of the anti-reflux mechanism. Development 134(20):3763-3769

6. Mackie GG, Awang H, Stephens FD (1975) The ureteric orifice: the embryologic key to radiologic status of duplex kidneys. J Pediatr Surg 10:473-481
7. Mackie GG, Stephens FD (1975) Duplex kidneys: a correlation of renal dysplasia with position of the ureteral orifice. J Urol 114:274-280

8. Paquin AJ (1959) Ureterovesical anastomosis: the description and evaluation of a technique. J Urol 82:573-583

9. Peters CA, Skoog SJ, Arant BS, Copp HL, Elder JS, Hudson RG, Khoury AE, Lorenzo AJ, Pohl HG, Shapiro E, Snodgrass WT, Diaz M (2010) Summary of the AUA guideline on management of primary vesicoureteral reflux in children. J Urol 184(3):1134 1144

10. Duckett JW, Bellinger M (1982) A plea for standardized grading of vesicoureteral reflux. Eur Urol 8:74-77

11. International Reflux Study Committee (1981) Medical versus surgical treatment of primary vesicoureteral reflux: report of the International Reflux Study Committee. Pediatrics 67:392-400

12. Knudson MJ, Austin JC, McMillan ZM, Hawtrey CE, Cooper CS (2007) Predictive factors of early spontaneous resolution in children with primary vesicoureteral reflux. J Urol 178:16841688

13. Skoog SJ, Belman AB, Majd M (1987) A nonsurgical approach to the management of primary vesicoureteral reflux. J Urol 138:941946

14. Austin JC, Cooper CS (2010) Vesicoureteral reflux: who benefits from correction. Urol Clin N Am 37:243-252

15. Shaikh N, Ewing AL, Bhatnagar S, Hoberman A (2010) Risk of renal scarring in children with a first urinary tract infection: a systematic review. Pediatrics 126(6):1-8

16. Elder JS, Peters CA, Arant BS, Ewalt DH, Hawtrey CE, Hurwitz RS, Parrott TS, Snyder HM, Weiss RA, Woolf SH, Hasselblad V (1997) Pediatric vesicoureteral reflux guidelines panel summary report on the management of primary vesicoureteral reflux in children. J Urol 157:1846-1851

17. Children's Hospital Boston (2011) VUR Resolution Rate Calculator, www.childrenshospital.org/vurcalculator

18. Jodal U, Smellie JM, Lax H, Hoyer PF (2006) Ten-year results of randomized treatment of children with severe vesicoureteral reflux. Final report of the International Reflux Study in Children. Pediatr Nephrol 21:785-792

19. Olbing H, Smellie JM, Jodal U, Lax H (2003) New renal scars in children with severe VUR: a 10-year study of randomized treatment. Pediatr Nephrol 18:1128-1131

20. Birmingham Reflux Study Group (1987) Prospective trial of operative versus non-operative treatment of severe vesicoureteric reflux in children: five years' observation. Birmingham Reflux Study Group. Br Med J 295:237-241

21. Hutch JA (1952) Vesicoureteral reflux in the paraplegic: cause and correction. J Urol 68:457-469

22. Lich R Jr (1961) Recurrent urosepsis in children. J Urol 86:554 558

23. Gregoir W, Van Regemorter G (1964) Le reflux vesico-ureteral congenital. Urol Int 18:122-136

24. Riedmiller H, Gerharz EW (2008) Antireflux surgery: LichGregoir extravesical ureteric tunneling. BJUI 101:1467-1482

25. Politano VA, Leadbetter WF (1958) An operative technique for the correction of vesicoureteral reflux. J Urol 79:932-941

26. Steffens J, Stark E, Haben B, Treiyer A (2006) PolitanoLeadbetter ureteric reimplantation. BJUI 98:695-712

27. Glenn JF, Anderson EE (1967) Distal tunnel ureteral reimplantation. J Urol 97:623-626

28. Glenn JF, Anderson EE (1978) Technical considerations in distant tunnel ureteral reimplantation. J Urol 119:194-198

29. Cohen SJ (1975) Uretozystoneostomie: eine neue antireflux Technik. Aktuelle Urol 6:1

30. Retik AB, Colodny AH, Bauer SB (1984) Genitourinary surgery: pediatric urology, vol 2. Churchill Livingston, NY, p 764 
31. Ehrlich RM, Gershman A, Fuchs G (1994) Laparoscopic vesicoureteroplasty in children: initial case reports. Urol 433:255-261

32. Janetschek G, Radmayr C, Bartsch G (1995) Laparoscopic ureteral anti-reflux plasty reimplantation. First clinical experience. Ann Urol 29:101-105

33. Hayn MH, Smaldone MC, Ost MC, Docimo SG (2008) Minimally invasive treatment of vesicoureteral reflux. Urol Clin N Am 35:477-488

34. Läckgren G, Kirsch AJ (2010) Endoscopic treatment of vesicoureteral reflux. BJUI 9(105):1332-1447

35. O’Donnell B, Puri P (1984) Treatment of vesicoureteric reflux by endoscopic injection of Teflon. Br Med J 289:7-9

36. Puri P, Pirker M, Mohanan N, Dawrant M, Dass L, Colhoun E (2006) Subureteral dextranomer/hyaluronic acid injection as first line treatment in the management of high grade vesicoureteral reflux. J Urol 176:1856-1860

37. Kirsch AJ, Perez-Brayfield M, Smith EA, Scherz HC (2004) The modified STING procedure to correct vesicoureteral reflux: improved results with submucosal implantation within the intramural ureter. J Urol 171:2413-2416

38. McMann LP, Scherz HC, Kirsch AJ (2007) Long-term preservation of dextranomer/hyaluronic acid copolymer implants after endoscopic treatment of vesicoureteral reflux in children: a sonographic volumetric analysis. J Urol 166:316-320

39. Routh JC, Reinberg Y, Ashley RA, Inman BA, Wolpert JJ, Vandersteen DR, Husmann DA, Kramer SA (2007) Multivariate comparison of the efficacy of intraureteral versus subtrigonal techniques of dextranomer/hyaluronic acid injection. J Urol 178:1702-1706

40. Yucel S, Gupta A, Snodgrass W (2007) Multivariate analysis of factors predicting success with dextranomer/hyaluronic acid injection for vesicoureteral reflux. J Urol 177(4):1505-1509

41. Gupta A, Snodgrass W (2008) Intra-orifice versus hydrodistention implantation technique in dextranomer/hyaluronic acid injection for vesicoureteral reflux. J Urol 180:1589-1593

42. Lavelle MT, Conlin MJ, Skoog SJ (2004) Subureteral injection of deflux for correction of reflux: analysis of factors predicting success. J Urol 65:564-567

43. Routh JC, Reinberg Y (2010) Predicting success in the endoscopic management of pediatric vesicoureteral reflux. Urol 76(1):195-198

44. Elder JS, Diaz M, Caldamone AA, Cendron M, Greenfield S, Hurwitz R, Kirsch A, Koyle MA, Pope J, Shapiro E (2006) Endoscopic therapy for vesicoureteral reflux: a meta-analysis. I. Reflux resolution and urinary tract infection. J Urol 175:716-722

45. Routh JC, Inman BA, Reinberg Y (2010) Dextranomer/Hyaluronic acid for pediatric vesicoureteral reflux: systematic review. Pediatrics 125(5):1010-1019

46. Holmdahl G, Brandström P, Läckgren G, Sillén U, Stokland E, Jodal U, Hansson S (2010) The Swedish reflux trial in children: II. Vesicoureteral reflux outcome. J Urol 184:280-285

47. Läckgren G, Wåhlin N, Sköldenberg E, Stenberg A (2001) Longterm followup of children treated with dextranomer/hyaluronic acid copolymer for vesicoureteral reflux. J Urol 166:1887-1892

48. Oswald J, Riccabona M, Lusuardi L, Bartsch G, Radmayr C (2002) Prospective comparison and 1-year follow-up of a single endoscopic subureteral polydimethylsiloxane versus dextranomer/ hyaluronic acid copolymer injection for treatment of vesicoureteral reflux in children. Urol 60(5):894-897

49. Lee EK, Gatti JM, Demarco RT, Murphy JP (2009) Long-term followup of dextranomer/hyaluronic acid injection for vesicoureteral reflux: late failure warrants continued followup. J Urol 181:1869-1875

50. Hsieh MH, Madden-Fuentes RJ, Lindsay NE, Roth DR (2010) Treatment of pediatric vesicoureteral reflux using endoscopic injection of hyaluronic acid/dextranomer gel: intermediate-term experience by a single surgeon. Urol 76(1):199-203

51. Brandström P, Esbjörner E, Herthelius M, Swerkersson S, Jodal U, Hansson S (2010) The Swedish reflux trial in children: III. Urinary tract infection pattern. J Urol 184:286-291

52. Weiss R, Duckett J, Spitzer A (1992) Results of a randomized clinical trial of medical versus surgical management of infants and children with grades III and IV primary vesicoureteral reflux (United States). J Urol 148:1667

53. Brandström P, Nevéus T, Sixt R, Stokland E, Jodal U, Hansson S (2010) The Swedish reflux trial in children: IV. Renal damage. J Urol 184:292-297

54. Chertin B, Natsheh A, Fridmans A, Shenfeld OZ, Farkas A (2009) Renal scarring and urinary tract infection after successful endoscopic correction of vesicoureteral reflux. J Urol 182:1703-1707

55. Benoit RM, Peele PB, Docimo SG (2006) The cost-effectiveness of dextranomer/hyaluronic acid copolymer for the management of vesicoureteral reflux: 1: substitution for surgical management. J Urol 176:1588-1592

56. Kobelt G, Canning DA, Hensle TW, Lackgren G (2003) The cost-effectiveness of endoscopic injection of dextranomer/ hyaluronic acid copolymer for vesicoureteral reflux. J Urol 169:1480-1485

57. Hensle TW, Grogg AL, Eaddy M (2007) Pediatric vesicoureteral reflux: treatment patterns and outcomes. Nat Clin Prac Urol 4 (9):462-463

58. Hsieh MH, Madden-Fuentes RJ, Bayne A, Munch E, Wildenfels P, Alexander SJ, Gonzales ET Jr, Cisek LJ, Jones EA, Roth DR (2010) Cross-sectional evaluation of parental decision making factors for vesicoureteral reflux management in children. J Urol 184:1589-1593

59. Routh JC, Nelson CP, Graham DA, Lieu TA (2010) Variation in surgical management of vesicoureteral reflux: influence of hospital and patient factors. Pediatrics 125(3):446-451

60. Kirsch AJ, Perez-Brayfield MR, Scherz HC (2003) Minimally invasive treatment of vesicoureteral reflux with endoscopic injection of dextranomer/hyaluronic acid copolymer: the Children's Hospitals of Atlanta experience. J Urol 170:211215

\section{Answers}

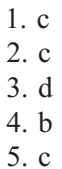

1. c

4. b

5. c 